Canadian Studies in Population, Vol. 30(1), 2003, pp. 179-192

\title{
Ramifications of Ostracism as a Consequence of Revelation of HIV Positive Status: Its Effect on Individuals and Families in Botswana
}

Tabitha T. Langeni

Department of Population Studies

University of Botswana

Gaborone, Botswana

\begin{abstract}
Using primary data and a combination of qualitative and quantitative methods the study looks into ramifications of ostracism as a factor influencing people's behavior towards the spread of HIV/AIDS, which have devastating effects on the structure and composition of the family in Botswana. The study showed that the highest proportion of respondents who would abandon an HIV positive partner (58.4\%) occurs among young people aged 15 to 19 years; and that the propensity to abandon an HIV positive partner diminishes with advancement in age. In-depth inquiries on why HIV positive partners would be abandoned produced responses that revolved around fear of exposure, vulnerability and association with an HIV positive individual. The study showed that the highest proportion of respondents who would not reveal their HIV positive status occurs among those who have lost a relative or a friend to AIDS. Fear of being isolated, rejected, stigmatized and unwanted featured among the top reasons why respondents would not reveal their HIV positive status. Society's reaction towards HIV positive individuals and families with HIV/AIDS patients appeared strong enough to drive individuals to hide their positive status and to go ahead and take the risk of onward transmission of the virus.
\end{abstract}

Key words: Ostracism, qualitative, quantitative, focus group discussions 
Tabitha T. Langeni

\section{Résumé}

Using primary data and a combination of qualitative and quantitative methods the study looks into ramifications of ostracism as a factor influencing people's behavior towards the spread of HIV/AIDS, which have devastating effects on the structure and composition of the family in Botswana. The study showed that the highest proportion of respondents who would abandon an HIV positive partner (58.4\%) occurs among young people aged 15 to 19 years; and that the propensity to abandon an HIV positive partner diminishes with advancement in age. In-depth inquiries on why HIV positive partners would be abandoned produced responses that revolved around fear of exposure, vulnerability and association with an HIV positive individual. The study showed that the highest proportion of respondents who would not reveal their HIV positive status occurs among those who have lost a relative or a friend to AIDS. Fear of being isolated, rejected, stigmatized and unwanted featured among the top reasons why respondents would not reveal their HIV positive status. Society's reaction towards HIV positive individuals and families with HIV/AIDS patients appeared strong enough to drive individuals to hide their positive status and to go ahead and take the risk of onward transmission of the virus.

Mots-clés: Ostracism, qualitative, quantitative, focus group discussions

\section{Introduction}

Botswana, which obtained its independence in 1966, is situated between latitudes 18 and 27 degrees South. It straddles the Tropic of Capricorn in the center of the Southern African Plateau and is bounded by Namibia in the West, Angola in the North-West, Zambia in the North, Zimbabwe in the North-East and South Africa in the East and the South. The population of Botswana was estimated at 1.3 million in 1991 and the preliminary figures for the 2001 census suggest a figure of about 1.7 million.

Up until now, researchers working on African Demography have been focusing on fertility decline, migration, sterility and/or infertility in Africa, but now there is a shift in the focus towards the AIDS epidemic currently engulfing the continent as a whole. With its open policy on immigration, which does not require screening of immigrants for possible carriers of deadly viruses, Botswana has not escaped the AIDS scourge and is currently experiencing 
Ramifications of Ostracism as a Consequence of Revelation of HIV Positive Status: Its Effect on Individuals and Families in Botswana

devastating consequences of its welcoming policy. The first case of HIV was discovered in 1985 and since then there has been a dramatic rise in the rate at which the HIV infection is spread. The dilemma faced by many people in Botswana is whether to reveal or not to reveal one's HIV positive status.

The implications of disclosure appear to be a concern, not only of families, but also of individuals already HIV positive as well as of those who are HIV negative and are still at risk of contracting the HIV virus. On one hand there is the thought that self-revelation of a positive HIV status has the potential to enhance trust and social acceptance in social relationships and to reduce the onwards transmission risks of the HIV virus in sexual relationships where at least one partner is HIV positive (Cusick and Rhodes, 1999). This school of thought propounds that knowledge of the risk involved is the key element in HIV risk avoidance and accepts that disclosure of HIV positivity to sexual partners is therefore the central issue in transmission prevention as well as being crucial in establishing full social acceptance and support for HIV positive individuals. On the other hand there is the thought that the people to whom one's HIV positive status is revealed might react in an unfavorable manner due to the existence of popular connotations of shame associated with HIV as a sexually transmitted disease, the negative judgments often made of HIV positive individuals as being sexually indiscriminate and promiscuous, and their condemnation as being morally irresponsible. All these factors might militate against one's willingness to disclose one's HIV positive status. Therefore, HIV/AIDS victims having well-founded fears of stigmatization if their condition should become known in their communities might end up keeping their HIV positive status to themselves in order to avoid ostracism, rejection, isolation and discrimination by the communities in which they live. Succinctly put, society's reactions towards people with HIV/AIDS can, on one hand, encourage HIV positive individuals to come forward and declare their HIV status or can, on the other, discourage them and cause them to hide their HIV status thus placing partners or anyone else at risk of contracting the disease.

The main problem at hand is that despite world-wide dissemination of information about AIDS through information campaigns and educational programs in the media, many people continue to get infected with the HIV virus and go on to develop AIDS. Surveys in Botswana suggest that people know a lot about HIV/AIDS. A survey conducted by the Ministry of Health on Monitoring Trends in Sexual Behavior in 1993 found that over 90\% of respondents knew the modes of transmission and that condom use could prevent transmission of AIDS. Several organizations have introduced programs to educate people about HIV/AIDS and are providing information and counseling to people on how to avoid and prevent HIV/AIDS. Because of this increased knowledge about AIDS and all the efforts made by several organizations to provide information on HIV/AIDS, the expectations were that the rate of infection would decline. However, these efforts appear fruitless since the number of people getting infected with HIV/AIDS increases daily at a disturbing rate. The national HIV 
Tabitha T. Langeni

prevalence rate is estimated at $38.6 \%$ and the estimated number of adults aged 15-49 years in Botswana who are infected with the HIV virus is 277637 (AIDS/STD Unit Technical Report, 2000). This is a high infection rate especially in a population of 1.6 million. These facts indicate that the way people behave is influenced by more than what they know. In such circumstances it becomes important to identify factors that influence behavior towards the spread of the deadly virus despite the observed high levels of knowledge about HIV/AIDS in the country.

Botswana has made great strides in increasing infant and child survival in recent decades but the gains are threatened by AIDS. The impact of AIDS on infant and child mortality rates will reverse the hard-won improvements on child survival. The phenomenal spread of HIV/AIDS also hampers the progress of Botswana as is evident in the current trend where funds that could be used elsewhere are used in HIV/AIDS programs. The HIV/AIDS epidemic is also likely to impact negatively on the age distribution of the population. The shift in population distribution will be towards children and the elderly people as young adult mortality increases due to the epidemic. The prevalence of infection is highest in young people aged 20-35 years (Modisaotsile, 1995). This will in turn increase the dependency ratio of the country as these are the productive ages and most of the people in these ages are the breadwinners in families.

There is also a rapid increase in the number of orphaned children in Botswana. The 1994 sentinel surveillance study estimated that the number of HIV/AIDS orphans would be more than 65000 by the year 2000 . These children are already proving to be a burden to the extended family, which in itself has been weakened by modernisation. A study on social consequences of AIDS was conducted in the Kgatleng district and it was noted that over $80 \%$ of orphan caretakers perceived them as a burden. Alongside the traditional male/femaleheaded households there is a rise in a third type, the child-headed households that stem from illnesses and deaths of adult heads of families.

It is the objective of this paper to examine some factors, which influence behaviour towards the spread of the HIV virus, and their effects on individuals and families in Botswana. It is hoped that the findings would help give guidance towards implementation of strategies that would improve society's perceptions and reactions towards HIV positive individuals and thus prevent onward transmission of the HIV virus.

\section{Material and Methods}

Primary data used were collected from a sample of 600 individuals, aged between the ages of 15 and 35. The sample was randomly selected from Old Naledi and Extension 14 for interview. Face to face interview method was used to administer the questionnaire. In addition to the questionnaires focus group 
Ramifications of Ostracism as a Consequence of Revelation of HIV Positive Status: Its Effect on Individuals and Families in Botswana

discussions were also conducted in each of the two areas. This was done primarily to get an in-depth explanation of quantitative findings of the canvasser method and of some of the issues that needed an in-depth discussion. Respondents were asked questions about their feelings towards people with HIV/AIDS. Situational questions were also asked in order to find out what they would do faced with a particular situation. From the answers received several variables were identified for use in the analysis. They include socioeconomic (cohabitation, employment), demographic (age, cause-specific mortality, locality), and behavioral factors (behavior towards HIV positive partner, selfrevelation of HIV positive status to anybody).

The chi-square test is used in the analysis to test for the effect of explanatory variables on the dependent variable. The dependent variable is dichotomous coded one if the respondent would abandon an HIV positive partner and zero otherwise. Since the dependent variable is a dichotomy, the use of the logistic regression technique is appropriate. With a dichotomous dependent variable, the constant variance assumption of the general linear model is violated and ordinary least square estimates are rendered inefficient. Likewise, because dichotomous variables can be non-normal in their distribution, the assumptions of a normal error term and the usual tests of significance for least square techniques are inappropriate.

\section{Limitations}

The use of focus group discussions has its own limitations in that some participants may be keen to express themselves but because of the presence of other participants in the group may not freely do so. However in this study the focus group was used in conjunction with quantitative method so that the two methods could supplement each other in some way. Also, opinions about AIDS and AIDS related issues differ remarkably between districts as well as within districts in Botswana. Therefore, the sample chosen may not be representative of the entire country.

\section{Results}

Asked how they would react if they were to discover that their partner was HIV positive while they themselves were HIV negative, $36.3 \%$ of respondents said they would abandon an HIV positive partner while the remaining $63.7 \%$ said they would stick by their HIV positive partner and continue with the relationship. 
Tabitha T. Langeni

\section{Age and Respondents' Reactions towards an HIV Positive Partner}

Age is a very important variable in the analysis of HIV and AIDS in Botswana in that HIV and AIDS disproportionately affect young people in the country. Around $50 \%$ of the new HIV infections are in the age group 15-24 years, the range in which most people start their sexual activities (UNAIDS HIV/AIDS REPORT, 1999). Table 1 depicts the effect of age on perceived reaction towards an HIV positive partner. The table shows that the highest proportion of respondents who would abandon an HIV positive partner is found among young people aged $15-19$ years $(58.4 \%)$. The table shows that the propensity to abandon an HIV positive partner diminishes with advancement in age. This could be attributable to the fact that young people have more years ahead of them, compared with those in the older age groups, in which to enjoy an HIV virus-free relationship if they should choose to abandon an HIV positive partner.

Table 1

Effect of Age on Respondent's Reaction towards an HIV Positive Partner

\begin{tabular}{llllll}
\hline & \multicolumn{5}{c}{ Age of Respondent } \\
$\begin{array}{l}\text { Reaction towards HIV } \\
\text { Positive Partner }\end{array}$ & $15-19$ & $20-24$ & $25-29$ & $30-34$ & Total \\
\hline & & & & & \\
& & & & & \\
Would continue relationship & $\mathrm{N}=42$ & $\mathrm{~N}=109$ & $\mathrm{~N}=80$ & $\mathrm{~N}=138$ & $\mathrm{~N}=369$ \\
with HIV positive partner & $41.6 \%$ & $58.9 \%$ & $69.0 \%$ & $78.0 \%$ & $63.7 \%$ \\
& & & & & \\
Would abandon HIV & $\mathrm{N}=59$ & $\mathrm{~N}=76$ & $\mathrm{~N}=36$ & $\mathrm{~N}=39$ & $\mathrm{~N}=210$ \\
positive partner & $58.4 \%$ & $41.1 \%$ & $31.0 \%$ & $22.0 \%$ & $36.3 \%$ \\
& & & & & \\
Total & $\mathrm{N}=101$ & $\mathrm{~N}=185$ & $\mathrm{~N}=116$ & $\mathrm{~N}=177$ & $\mathrm{~N}=579$ \\
& $100.0 \%$ & $100.0 \%$ & $100.0 \%$ & $100.0 \%$ & $100.0 \%$ \\
& & & & & \\
\hline
\end{tabular}

During the focus group discussions it was revealed that younger participants would readily abandon an HIV positive partner and that they live in fear of contracting the disease. Upon being asked why they would abandon an HIV positive partner, a nineteen-year-old female said:

"because I would always be afraid that I would get it (the HIV virus), also I don't think I could handle the pressure of watching somebody die. " 
Meanwhile respondents in the older age groups are likely to have had their relationships for a comparatively longer period and probably more stable and more committed to their relationships compared to the younger group. Perry at al. (1994) point out that new relationships are more susceptible to breakdown in the light of HIV infection. The table indicates that there is a significant association between age and one's reaction towards an HIV positive partner $\left(\chi^{2}\right.$ $=40.177 ; \mathrm{df}=3 ; \mathrm{P}=0.000)$.

\section{Employment Status and Reaction towards HIV Positive Partner}

Unemployment implies lack of regular source of income and therefore inability to afford commodities outside those that appear to be bare necessities. Family members spend a lot of money when consulting traditional healers and paying medical bills as they continue to seek treatment for prolonged HIV opportunistic infections. The households are also incurring financial burdens from funeral rituals like paying mortuaries, buying coffins and food for the mourners. When asked what they would do if they were to discover that their partner was HIV positive while they themselves were not, employed people responded differently from those unemployed. The highest proportion of those respondents who would abandon their HIV positive partner was found among those who were unemployed (42.4\%) as shown in Table 2. There is also a significant association between employment status and reaction towards an HIV positive partner $\left(\chi^{2}=13.253 ; \mathrm{P}=0.000\right)$.

Table 2

Effect of Employment Status on Respondent's Reaction towards an HIV Positive Partner

\begin{tabular}{lccc}
\hline \multicolumn{1}{c}{ Reaction towards } & Employment Status & & \\
HIV Positive Partner & Employed & Unemployed & Total \\
\hline Would continue relationship & $\mathrm{N}=175$ & $\mathrm{~N}=194$ & $\mathrm{~N}=369$ \\
with HIV positive partner & $72 . .3 \%$ & $57.6 \%$ & $63.7 \%$ \\
Would abandon HIV & & & \\
positive partner & $\mathrm{N}=67$ & $\mathrm{~N}=143$ & $\mathrm{~N}=210$ \\
& $27.7 \%$ & $42.4 \%$ & $36.3 \%$ \\
Total & & & $\mathrm{N}=579$ \\
& $\mathrm{~N}=242$ & $\mathrm{~N}=337$ & $100.0 \%$ \\
\hline
\end{tabular}


Tabitha T. Langeni

\section{Living Arrangement and Reaction towards HIV Positive Partner}

Living together as partners implies a more serious type and more commitment in a relationship, compared to a relationship where there is occasional visitation. Responses from the survey showed that people who live together as couples are more likely to continue the relationship with an HIV positive partner. Table 3 shows the effect of living arrangement on perceived reaction towards HIV positive partner. The table shows that very few people living together would abandon a partner that is HIV positive. The highest proportion of respondents who would abandon an HIV positive partner occurs among those who do not live together (42.4\%). People who would continue the relationship with an HIV positive partner were mostly among those who live together $(69.2 \%)$. The table also shows that there is a significant association between living arrangement and one's reaction towards an HIV positive partner $\left(\chi^{2}=8.185\right.$ and $\left.\mathrm{P}=0.004\right)$.

Probable reasons for abandoning an HIV positive partner by the young, the unemployed and by those who live away from their partners could be the inability to handle complex emotional problems and fear of commitment to their partners.

Table 3

Effect of Living Arrangement on Respondent's Reaction towards an HIV Positive Partner

\begin{tabular}{lccc}
\hline \multicolumn{1}{c}{ Reaction towards } & Living Arrangement & & \\
\multicolumn{1}{c}{ HIV Positive Partner } & Together & Not Together & Total \\
\hline $\begin{array}{l}\text { Would continue relationship } \\
\text { with HIV positive partner }\end{array}$ & $\mathrm{N}=209$ & $\mathrm{~N}=160$ & $\mathrm{~N}=369$ \\
& $69.2 \%$ & $57.8 \%$ & $63.7 \%$ \\
$\begin{array}{l}\text { Would abandon HIV } \\
\text { positive partner }\end{array}$ & $\mathrm{N}=93$ & $\mathrm{~N}=117$ & $\mathrm{~N}=210$ \\
& $30.8 \%$ & $42.2 \%$ & $36.3 \%$ \\
Total & $\mathrm{N}=302$ & $\mathrm{~N}=277$ & $\mathrm{~N}=579$ \\
& $100.0 \%$ & $100.0 \%$ & $100.0 \%$ \\
& & & \\
\hline
\end{tabular}

\section{Self-revelation of HIV Positive Status}

Respondents were asked whether they would reveal their status to anyone if they were to discover that they themselves were HIV positive. The act of revealing one's HIV positive status has repercussions both ways. Revealing one's HIV positive status may have negative results in that the people to whom the positive 
Ramifications of Ostracism as a Consequence of Revelation of HIV Positive Status: Its Effect on Individuals and Families in Botswana

status has been revealed may either spread the acquired information far and wide, may stigmatize, isolate, ridicule, and pass negative judgments on the HIV positive individual. On the other hand, revealing one's HIV positive status may enhance trust, acceptance and respect by the people to whom the status has been revealed. It also empowers those around the HIV positive individual with knowledge of the risks involved in dealing with him /her and thus help prevent onward transmission of the deadly virus. Responses to this question were interesting in that only $33.9 \%$ of respondents said they would not reveal their HIV status to anyone while the remaining majority $(66.1 \%)$ said they would reveal their HIV positive status. However, where exposure to HIV/AIDS was brought home to individuals according to what they had experienced in the past, true revelations came to the fore. Respondents were asked if they had lost a relative or a friend to AIDS. From the answers to that question the variable, mortality experience, was obtained (coded one if respondent had lost a relative/friend to AIDS or zero otherwise).

Table 4 depicts a distribution of respondents who have lost a relative or a friend to AIDS classified by willingness to reveal one's HIV positive status. The table shows that the highest proportion of respondents who would not reveal their HIV positive status $(42.3 \%)$ occurs among those who had lost a relative or a friend to AIDS, meanwhile revelation of HIV positive status would occur mostly among those who had not lost a relative to AIDS (71.9\%). Probable reasons why people who had lost a relative to AIDS would not reveal their positive status to a friend could be that having had the experience of how society and friends reacted towards the relative or friend upon being acknowledged as having AIDS, they would not like a repeat of what they witnessed happening to them. Evidence appears to be suggesting that families that have AIDS patients and the people that are infected are being stigmatized.

In the focus group discussions participants who said they would not reveal their HIV status were asked why they would not do so. A sixteen-year-old female said:

"My fear would be that my friends would not want to touch me, or hug me or be with me anymore, and people would not understand and they would not embrace me."

Fear of ostracism was reflected in some of the responses, which came forth from the focus group discussion. A twenty seven year old man who would not reveal his HIV status to anybody said:

"I know of a 24 year old male who was a famous football player and during his football playing days he had many friends and fans who adored him, but once it became known that he had HIVIAIDS all his friends abandoned him. He spent his last days alone. ", 
Tabitha T. Langeni

Table 4

Effect of Losing a Relative/Friend to AIDS on Willingness

to Reveal One's Positive HIV Status

\begin{tabular}{lccc}
\hline \multicolumn{1}{c}{ Lost a Relative to AIDs } \\
$\begin{array}{l}\text { Willingness to Reveal } \\
\text { One's Positive HIV Status }\end{array}$ & Yes & No & Total \\
\hline Would reveal positive & $\mathrm{N}=135$ & $\mathrm{~N}=248$ & $\mathrm{~N}=369$ \\
HIV status to a friend & $57.7 \%$ & $71.9 \%$ & $63.7 \%$ \\
& & & \\
Would not reveal positive & $\mathrm{N}=99$ & $\mathrm{~N}=97$ & $\mathrm{~N}=210$ \\
HIV status to a friend & $42.3 \%$ & $28.1 \%$ & $36.3 \%$ \\
& & & $\mathrm{~N}=579$ \\
Total & $\mathrm{N}=234$ & $\mathrm{~N}=345$ & $100.0 \%$ \\
& $100.0 \%$ & $100.0 \%$ & \\
\hline
\end{tabular}

The same participant, recalling an incident he observed about a colleague who was once popular said:

"When 39 year old entered the hall where a meeting was going to be held, he identified the faces of his friends and moved towards them but they turned their faces away from him and moved away. He pulled a chair and sat down among other colleagues, but one by one everyone moved away and left him sitting alone. When he became seriously ill none of his friends went to even visit him in hospital. "

Having witnessed this and several more incidents this participant said:

" I would rather take more precautions by using a condom if I care about my partner or just continue having unprotected sex if I don't care, but I would never disclose my status to anyone if I were to discover I was HIV positive. It would remain my secret and when the time came for the disease to begin making me ill, I would rather die with dignity and end it all without exposing my family to indignities and stigmatisation from the society.

Society's reaction towards HIV positive individuals appears to have a very strong influence on individual behavior.

In the meantime the family structure is disintegrating further because the caregivers and breadwinners in the home are dying and families are left with no one to depend on so the members have to go and live with other members of the extended family for support. People who have not lost any relative or friend to 
Ramifications of Ostracism as a Consequence of Revelation of HIV Positive Status: Its Effect on Individuals and Families in Botswana

AIDS are probably far from the problem of societal ostracism and have not been closely involved in the experience of watching a friend or a loved one being stigmatised, isolated and shunned by society and former friends and relatives. The table further indicates that there is a significant association between AIDSspecific mortality and revelation of one's HIV positive status $\left(\chi^{2}=12.541 ; \mathrm{P}=\right.$ $0.000)$

\section{Logistic Regression}

The logistic regression technique was used to determine the partial effect of each explanatory variable on the dependent variable, holding all the other explanatory variables constant. Table 5 shows the results of the logistic regression, which estimates the effect of age, living arrangement, employment, locality and selfrevelation of HIV positive status to a friend on the likelihood of abandoning an HIV positive partner. All the explanatory variables were entered as dummy variables.

Table 5

Logistic Coefficients Predicting the Relative Odds of Abandoning an HIV Positive Partner in Botswana, 2001

\begin{tabular}{lcccc}
\hline \multicolumn{1}{c}{ Variable } & $\boldsymbol{\beta}$ & S.E. & Sig. & $\operatorname{Exp~} \boldsymbol{\beta}$ \\
\hline $\begin{array}{l}\text { Would not reveal } \\
\text { HIV status }\end{array}$ & 0.502 & 0.189 & 0.000 & 1.652 \\
Aged 15-24 & 0.727 & 0.193 & 0.000 & 2.069 \\
Not Living Together & 0.410 & 0.186 & 0.027 & 1.507 \\
Employed & -0.455 & 0.192 & 0.018 & 0.635 \\
Lives in Old Naledi & 0.577 & 0.189 & 0.000 & 1.782 \\
Constant & -1.523 & 0.245 & 0.000 & \\
\hline
\end{tabular}


Tabitha T. Langeni

The results show that respondents who are aged 15-24 years are significantly more likely to abandon an HIV positive partner. Being young (15-24years), as opposed to being older (25-34) multiplies the odds of abandoning HIV positive partner 2.07 times.

Being employed significantly reduces the chances of abandoning an HIV positive partner hence the negative relationship in the analysis.Living away from the partner showed a positive relationship with the likelihood of abandoning an HIV positive partner. This relationship was highly significant. This analysis shows that respondents who live with their partners are less likely to abandon their HIV positive partner. Living separately multiplies the odds of abandoning an HIV positive partner 1.51 times.

Results of this analysis show that residents of Old Naledi are significantly more likely to abandon an HIV positive partner when compared with those of Extension 14. Old Naledi and Extension 14 are both low cost areas in Gaborone, the Capital city of Botswana. However, while Old Naledi is a squatter settlement, Extension 14 is not. Old Naledi was not planned as a permanent settlement. It had been built as a temporary shelter for construction workers when Gaborone was being constructed in 1964. Ever since it was built, its social conditions have always been deplorable. Even though statistics of unemployment are not reliable, unemployment is estimated to be higher in Old Naledi than anywhere else in Gaborone. A 47\% unemployment rate was estimated in 1980 (CSO, 1986). The higher unemployment rate could probably be one of the factors explaining why there is a higher probability to abandon an HIV positive partner there compared to Extension 14.

The study also shows that respondents who would not reveal their HIV positive status to a friend are highly likely to abandon their HIV positive partner. Nondisclosure of HIV positive status multiplies the odds of abandoning an HIV positive partner 1.65 times.

\section{Conclusions and Recommendations}

The main objective of this paper was to examine the ramifications of ostracism as a factor which influences behaviour towards the spread of the HIV virus, and their effects on individuals and families in Botswana. The overall results of the study showed that the young and the unemployed respondents, as well as those respondents who do not live together with their partners are much more likely to abandon an HIV positive partner. The study also showed that fear of ostracism greatly influences decisions about whether to reveal or not to reveal one's HIV positive status.

It is therefore appropriate to conclude that it is probably because of fear of such rejections and ostracism (or other reasons that are a subset of those) that a large 
Ramifications of Ostracism as a Consequence of Revelation of HIV Positive Status: Its Effect on Individuals and Families in Botswana

majority of HIV positive people would rather keep their status to themselves. Education of society therefore becomes the greatest challenge because, until the society gets it right, only a handful of HIV positive individuals will come forward and self-disclose their HIV status. It is suggested that the Government of Botswana, with some assistance from Non Governmental Organizations rather than concentrating on imparting knowledge on how to avoid contracting the virus, should also attempt to educate the society on how to behave towards those who have the virus and encourage voluntary self disclosure of HIV positive individuals in order to empower those who are still HIV negative with knowledge of those with whom greater care has to be exercised. Massive education programs, using high profile people who are either infected themselves or empathetic to the victims could educate and sensitize the population at large in order to reduce fear of exposure among those infected with the virus in order to turn fear and rejection into empathy and inclusion. It is important for society to share responsibility for transmission prevention by encouraging disclosure on the part of HIV positive individuals. Fear does not make people change their behavior but encouragement, education, support and compassion do.

\section{References:}

Botswana Government 1986: Household Income and Expenditure Survey: 1985/1986. Central Statistics Office. Government Printers. Gaborone.

Botswana Government Annual Sentinel Surveillance Reports 1992 to 2000: AIDS STD Unit, Ministry of Health

Botswana Government: National Development Plan 8 (1997). Ministry of Finance and Development Planning. Government Printer. Gaborone.

Botswana Government Population And Housing Census: Population Projections 1991 to 2001. Central Statistics Office. Government Printers. Gaborone.

Botswana Government 1993: Monitoring trends in Youth sexual Behavior. AIDS/STD Unit. Ministry of Health. Gaborone.

Cusick, L., and T. Rhodes (1999): "The process of disclosing positive HIV status: findings from qualitative research" in Culture, Health \& Sexuality. 1999, Vol 1 No 1. 3-18 Netherlands

Modisaotsile, I. (1995): "HIV/AIDS Epidemic in Botswana: The Anticipated Demographic Consequences" in Botswana Government 1991 Population and Housing Census Dissemination Seminar, 1-4 May 1995. Gaborone Botswana. Pages 115-130 
Tabitha T. Langeni

Perry, S.W., C.A.L. Card, M. Moffart, T. Ashman, B.Fisherman, and L.B. Jacobsen (1994): "Self disclosure of HIV infection to sexual partners after repeated counseling." AIDS Education and Prevention, 6, 403-411

UNAIDS HIV/AIDS Report. December 1999 